\title{
GESTÃO PÚBLICA X AUTOGESTÃO NA PRODUÇÃO DAS UNIDADES HABITACIONAIS 1
}

\author{
SOUZA, Letícia de Paula
}

Universidade Federal de Uberlândia, e-mail: lepaulasouza@gmail.com

\begin{abstract}
RESUMO
Objetiva-se investigar o processo de inclusão sócio-espacial a partir de políticas e projetos de Habitações de Interesse Social, realizando-se um comparativo entre dois conjuntos habitacionais: o Shopping Park, em Uberlândia - MG, marcado por um processo fortemente centralizado e de gerência pela administração pública municipal em parceria com grandes construtoras, representando a produção massiva do programa Minha Casa Minha Vida (MCMV); e o Paulo Freire, em São Paulo - SP, com origem vinculada aos movimentos sociais e pautada num programa de autogestão. Utiliza-se o método bibliográfico, com levantamento específico sobre o processo histórico de cada conjunto, além da análise acerca da inserção urbana e da tipologia arquitetônica, associando-os aos conceitos de vitalidade, urbanidade e segregação urbana. Conclui-se que o conjunto habitacional desenvolvido pelo MCMV possui estrita relação com os princípios do urbanismo moderno, ocasionando problemas de segregação sócio-espacial e falta de vitalidade, ao passo que o sistema de coprodução assume uma visão mais contemporânea de cidade, com valorização da diversidade funcional, tipológica e social, dando ênfase nas relações coletivas e na apropriação do espaço público.
\end{abstract}

Palavras-chave: habitação social; urbanidade; vitalidade; segregação.

\begin{abstract}
The objective of this paper is to investigate the socio-spatial inclusion process based on social housing policies and projects, comparing two housing estates: Shopping Park, in Uberlândia MG, marked by a strongly centralized process and management by the municipal public administration in partnership with large construction companies, representing the massive production of the Minha Casa Minha Vida (MCMV) program; and Paulo Freire, in São Paulo - SP, whose origin is linked to social movements and based on a self-management program. The bibliographical method is used, with a specific survey on the historical process of each set, as well as the analysis of the urban insertion and the architectural typology, associating them with the concepts of vitality, urbanity and urban segregation. It is concluded that the housing complex developed by the MCMV has a strict relation with the principles of modern urbanism, causing problems of socio-spatial segregation and lack of vitality, while the coproduction system assumes a more contemporary view of the city, with a functional, typological and social diversity, with emphasis on collective relations and the appropriation of the public space.
\end{abstract}

Keywords: social habitation; urbanity; vitality; segregation

\section{INTRODUÇÃO}

As atuais discussões acerca da moradia de interesse social apontam para disparidade entre o conceito de urbanidade e a prática do atual planejamento urbano. Elas se concentram tanto na produção de cidades integradas que valorizem a diversidade humana, com a produção de espaços

SOUZA, L. P. Gestão Pública X Autogestão na Produção das Unidades Habitacionais. In: SIMPÓSIO BRASILEIRO DE QUALIDADE DO PROJETO NO AMBIENTE CONSTRUÍDO, 6., 2019, Uberlândia. Anais... Uberlândia: PPGAU/FAUeD/UFU, 2019. p. 115-125. DOI https://doi.org/10.14393/sbqp19012.

1 Este artigo foi desenvolvido na disciplina de Teoria do Urbanismo III, da Graduação em Arquitetura e Urbanismo da Universidade Federal de Uberlândia, em 2017. 
social e ambientalmente sustentáveis, quanto na concretização da cidade a partir de suas unidades habitacionais, que se expandem seguindo um modelo excludente, que torna a cidade um conjunto desarticulado. Desde a sistematização de políticas de combate ao déficit habitacional em 2002, as cidades brasileiras viveram período de intenso crescimento, impulsionado pela expansão dos conjuntos habitacionais de interesse social, cuja massificação aparece muito mais relacionada à industrialização da habitação do que às diretrizes abalizadas pelo projeto participativo.

O convívio entre as distintas funções urbanas - morar, trabalhar, passear, comprar, conviver, circular - são a base da vitalidade urbana e sua eliminação, por meio de maus projetos, comprometem a própria permanência da vida urbana e da cidade. Nesse sentido, os conjuntos habitacionais devem garantir não apenas o direito à moradia, mas também ambientes de convívio, trabalho, lazer e circulação. A falta desses elementos, aliados à ausência de infraestrutura básica, faz com que os cidadãos não sejam integrados à sociedade e aos direitos que a cidade possa proporcionar, ocasionando o fenômeno da segregação sócio-espacial.

Dessa forma, a proposta deste escrito é investigar e comparar o processo histórico de formação, associado à análise do local de implantação e suas tipologias arquitetônicas, além dos materiais e técnicas construtivas, refletindo sobre a influência do usuário ou não no projeto final, de dois conjuntos habitacionais de interesse social, Shopping Park e Paulo Freire, sendo o primeiro fruto de produção centralizada e massificada, desenvolvido por empreiteiras, enquanto o segundo se afigura como decorrência da associação entre a população, assessoria técnica arquitetônica e a administração pública municipal.

O marco teórico se concentra no conceito de urbanidade apresentado por Aguiar (2012), para quem tal noção está relacionada ao acolhimento das pessoas pelos espaços da cidade, como espaços hospitaleiros. Além disso, também toma por base a lição de Jacobs (2014), segundo a qual as compreensões de urbanidade e vitalidade possuem íntima relação, não sendo possível a existência da primeira sem a outra, visto que a vitalidade urbana é matéria-prima da urbanidade.

Perpassando pela expansão dessas políticas habitacionais, o trabalho é dividido em três capítulos. Inicialmente, aborda-se a questão teóricoconceitual sobre o desenvolvimento dos programas habitacionais de interesse social e o processo participativo e de autogestão da administração pública. $O$ segundo dá enfoque ao contexto e explicação acerca dos conjuntos analisados, bem como de suas características urbanas e arquitetônicas. Finalmente, parte-se para a comparação dos exemplos em estudo.

\section{HABITAÇÃO, PARTICIPAÇÃO POPULAR E AUTOGESTÃO PÚBLICA: DISCUSSÃO TEÓRICA}

A partir de 2002, tem início um programa sistemático de combate ao déficit de moradia coordenado pelo Governo Federal, cuja ideia primeira era a de desenvolver medidas descentralizadas, com recursos advindos do Fundo Nacional de Habitação de Interesse Social (FNHIS). Para que os estados e municípios pudessem integrar esse novel sistema, deveriam aderir à estrutura de criação de fundos, conselhos e planos locais de Habitação de Interesse Social (HIS), de maneira a garantir sustentabilidade, racionalidade e participação democrática na definição e implementação dos projetos. 
O programa apresentou interesses econômicos que iam além da questão da moradia, visto que foi utilizado como uma política econômica, o que, por muitas vezes, gerou conflitos. Se por um lado as políticas de combate ao déficit habitacional deveriam compor um projeto urbanístico que refletisse os interesses sociais e garantisse moradia de qualidade à população, por outro, tem-se que os empreendimentos habitacionais são produzidos em série, no qual esse grande contingente de residências atendem apenas aos interesses econômicos.

Diante do conflito de interesses, os princípios democráticos e participativos existentes na teoria deram lugar ao programa de interesse social Minha Casa Minha Vida (MCMV), que tinha por finalidade básica o combate à falta de moradia. Contudo, a confusão entre os interesses econômicos e a falta de conhecimento urbanístico transformou o MCMV em instrumento legislativo e financeiro altamente burocratizado, que acabou se concretizando pela atuação de grandes construtoras intermediadas pelo poder público municipal, excluindo, na maioria das vezes, a população que deveria ser beneficiada no processo de concepção projetual.

Os empreendimentos habitacionais são comercializados no mercado e as relações entre o projetista, empreendedor e usuário são desconhecidas. O usuário não participa diretamente dos procedimentos, considerado, conforme coloca Malard (2006, p. 6), "consumidor potencial", no qual o produto final é subjetivo e molda as preferências do mercado consumidor de moradias, ou seja, as pessoas são induzidas a habitarem conforme ditado pela indústria arquitetônica.

Criado em 2009, o MCMV surge com o objetivo de atender a demanda e o déficit habitacional, partindo-se da divisão da população de acordo com a renda média percebida, conforme a Classe 1 e 2, composta por famílias de renda entre zero e três salários mínimos, para as quais a atuação governamental ocorre por meio de subsídios, aplicados em parceria com os municípios. Além deste, alguns critérios utilizados são a existência de famílias em áreas de risco e insalubridade, com mulheres responsáveis pela unidade familiar ou que sejam residentes no município de Uberlândia há pelo menos dez anos, entre outros.

Sobre esse aspecto, Jacobs (2014, p. 219) ressalta que:

\begin{abstract}
Mesmo que os Utópicos tivessem planos que socialmente fizessem sentido nas cidades, está errado separar uma parte da população, segregada pela renda, separada em seus próprios bairros, que têm uma organização comunitária própria e diferente. Segregados, mas iguais não resulta senão em problema numa sociedade em que não se ensina às pessoas que a casta faz parte da ordem divina. Segregados, mas em melhores condições é uma contradição intrínseca onde quer que a separação seja imposta por uma forma de inferioridade.
\end{abstract}

Ao criarmos grupos a partir do critério de renda, desprezam-se diversos fatores que contribuem para a urbanidade das cidades, rompendo-se com as relações de vizinhança, seus vínculos e sentimento de pertencimento a um lugar. Além disso, os demais parâmetros utilizados pelo programa acabam por rotular as pessoas conforme suas condições e, por consequência, potencializar ainda mais os problemas sociais. Esse processo de segregação é reforçado pela atuação das empreiteiras, vez que as prefeituras não determinam os elementos que garantem um nível satisfatório de urbanidade, além de produzirem projetos nas periferias desconsiderando as características locais e 
reproduzindo grande número de residências idênticas, pois se busca o ganho financeiro pela produção massiva, conforme assevera Malard (2006), como uma indústria arquitetônica mediada pelo usuário padrão nos planos dos negócios imobiliários habitacionais.

Acerca da implementação acelerada de grandes conjuntos habitacionais, Jacobs (2014) sinaliza que há forte tendência à homogeneização dos espaços e que esse processo atua diretamente contra a diversidade urbana, o que, por sua vez, gera espaços monótonos, com pouca ou nenhuma vitalidade.

Uma substituição muito rápida, além de militar
economicamente contra a diversidade urbana e gerar o efeito
padronizado e desnaturado da construção de conjuntos
habitacionais, atuaria em sentido contrário à meta de o maior
número possível de pessoas permanecer espontaneamente por
muito tempo - moradores de prédios velhos ou novos e
moradores com ideias próprias a respeito de construção e
renovação (JACOBS, 2014, p. 225).

Apesar das contribuições sociais resultantes do MCMV, a busca pela urbanidade foi negligenciada do ponto de vista territorial, de reeducação e transformação socioespacial necessária a esses conjuntos, evidenciando a importância da reflexão crítica e a proposição de diferentes formas da produção de moradias de interesse social.

Não obstante a discussão sobre arquitetura participativa ser recente no debate contemporâneo de arquitetura e urbanismo, o arquiteto italiano Giancarlo de Carlo foi pioneiro, nas décadas de sessenta e setenta, na reflexão sobre a importância desse tema na criação de trabalhos que incorporassem a presença do usuário nos processos projetuais. Compreendiase que a importância da relação entre arquitetura e urbanismo, por meio da interação do habitante a um lugar, era mais que possuir uma casa, era pertencer a um lugar e se apropriar dele como parte da cidade (BARONE, 2005, p. 18).

O processo participativo é visto como uma forma de enfrentar a dimensão sociopolítica de projetos de interesse coletivo, levando a opinião dos usuários em consideração e fazendo valer a democracia e a cidadania na concepção dos espaços urbanos. Nesse novo modelo, os agentes constroem juntos, buscando soluções que atendam aos interesses dos usuários, ao mesmo tempo em que se enquadram nas disponibilidades técnicas e financeiras de cada projeto. Embora não seja a proposta de Jane Jacobs, o processo de coprodução surge como uma solução aos problemas urbanos apontados.

A urbanidade e a produção na escala do corpo podem ser entendidas como a base pela qual esse tipo de produção se desenvolve. Na produção participativa, os agentes constroem a partir de atividades cotidianas, sendo uma alternativa de combate ao processo de segregação socioespacial, adequando-se às reais necessidades humanas, na busca por um urbanismo humanizado, como pregava Giancarlo de Carlo (BARONE, 2005, p. 22) e como justificado por Maricato (apud BONDUKI, 1997, p. 41):

A participação da população no orçamento municipal, nos planos locais, ou até mesmo no projeto e na gestão dos recursos de sua futura casa, é a alternativa mais ética, mais solidária e também mais sustentável pelos seus efeitos ambientais sinergéticos. Do ponto de vista econômico, garante-se a eficácia na aplicação dos recursos e sua fiscalização. 
A estruturação, crescimento e desenvolvimento dos processos coparticipativos geram projetos com alto grau de urbanidade. Dessa forma, o FNHIS surge como alternativa à sistematização desses projetos e como medida para viabilizar a produção arquitetônica na escala do corpo e, ainda que a produção participativa resulte em projetos urbanos com maior integração sócio-espacial, seu desenvolvimento conflita com os interesses das políticas econômicas governamentais e das grandes construtoras.

\section{A CIDADE DE UBERLÂNDIA E O CASO DO SHOPPING PARK}

No ano de 1990 foi criado, na cidade de Uberlândia, o Plano de Ação Imediata para Habitação, em resposta à expansão da cidade, que passou por crescimento desde os anos quarenta, como resultado da indústria e do aumento da mão de obra advinda do processo migratório, gerando uma demanda por moradia. Logo na sequência surge o MCMV, que procurava solucionar o problema da falta de moradia, decorrente do crescimento urbano e populacional, sobretudo das famílias de baixa renda. Contudo, devido ao mercado imobiliário, tais construções são feitas em áreas dispersas da cidade, localizadas na periferia e, na maioria das vezes, sem infraestrutura adequada.

Assim, o bairro Shopping Park é um exemplo do processo de segregação que - MCMV causa devido à sua implantação nas franjas da cidade. A implantação do conjunto habitacional deslocado do centro urbano só foi possível por força do programa de habitação social, que, entre 2007 e 2009, construiu 3600 unidades habitacionais, sem qualquer tipo de relação com seu entorno. Sobre esse ponto de vista, Jacobs (2014) destaca que a implantação intempestiva de grandes conjuntos habitacionais povoados por grupos que não possuem nenhum vínculo é um dos efeitos do esvaziamento das ruas e da pouca relação de vizinhança, o que, por sua vez, causa um sentimento de insegurança.

No entanto, houve investimentos em moradias desproporcionais ao investimento em infraestrutura. Além disso, após a vinculação do MCMV ao Programa de Aceleração do Crescimento (PAC), até mesmo as normas de urbanidade foram flexibilizadas, permitindo, por exemplo, a implantação multifamiliar em um único lote de 16×25 metros, que posteriormente foi dividida em dois lotes de 8x25 metros, com duas unidades unifamiliares geminadas, com dimensões mínimas inferiores a permitida pela legislação municipal.

O Shopping Park é um grande empreendimento de habitação social de Uberlândia, localizado na região Sul da cidade, conforme mostra o mapa abaixo (Figura 1).

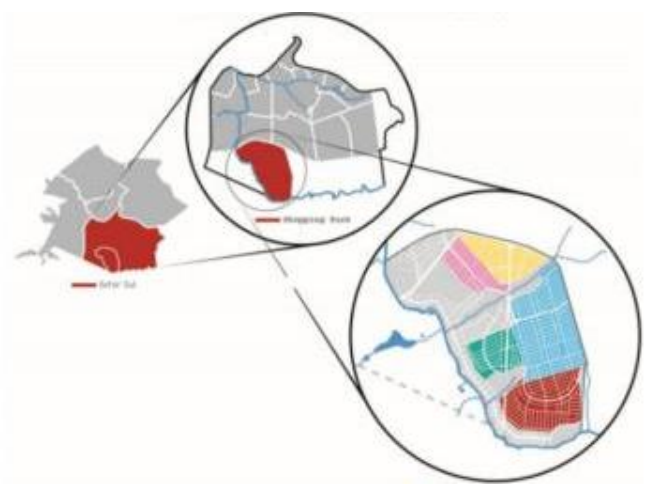

Figura 1 - Setor e bairro

Fonte: VILLA, S. B. et al., 2017. 
Conforme demonstrado por Villa, S. B. et al. (2017), historicamente, o bairro surgiu a partir de lotes ilegais, os quais foram aprovados somente em 1992, quando passaram a ter investimentos de caráter especulativo, dentre eles a construção de habitações sociais por meio do MCMV, que estimula o crescimento da população e fomenta o aumento da demanda por mais infraestrutura e equipamentos.

Como mostra a Figura 2, a inserção do bairro está afastada das áreas centrais da cidade, devido ao baixo valor das terras em que os lotes do conjunto estão inseridos. Desse modo, o acesso ao bairro é dificultado devido à insuficiência do transporte público em atender toda a demanda da área, isolando-o. Notase um desenho urbano desconexo da rede viária e com baixa qualidade urbana.

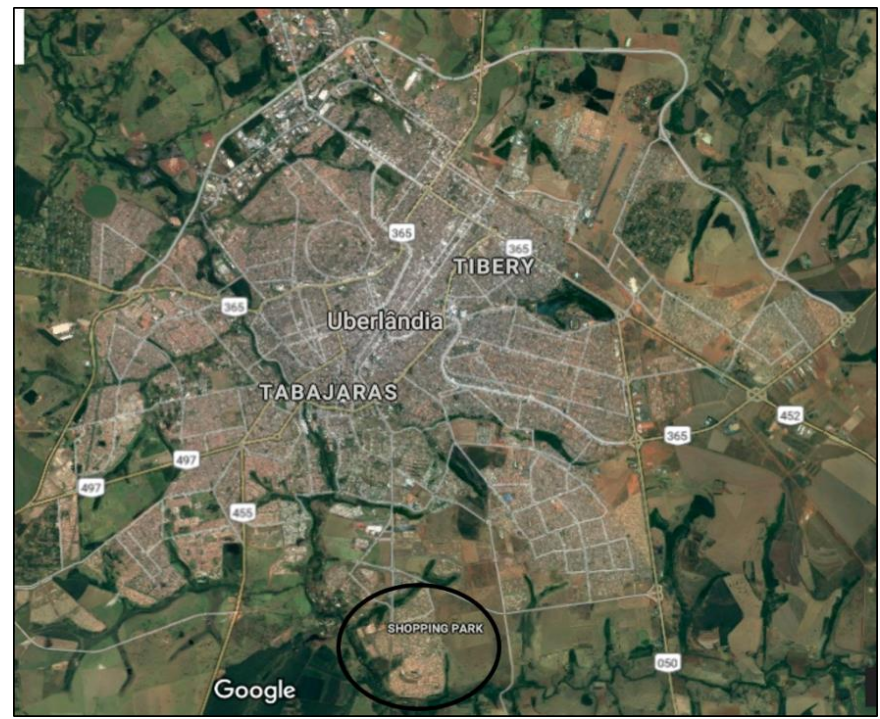

Figura 2 - Localização do bairro Shopping Park em relação à cidade

Fonte: Google Maps, 2019.

Analisando a porção sul do bairro, local em que situa a grande faixa de moradias em nível térreo, vê-se que elas são dispostas em terreno de grande declive, acarretando muitas vezes risco de desmoronamentos. A implantação é fixada com área mínima de $32 \mathrm{~m}^{2}$ para unidades que não possuem área de serviço e $36 \mathrm{~m}^{2}$ para unidades acessíveis.

Conforme observado na Figura 3, a habitação é localizada no centro do terreno, com produção de duas unidades geminadas, divididas em dois lotes de $8 \times 25$ metros. A planta é organizada com base no modelo de família nuclear tradicional, possuindo dois quartos, sala, cozinha, banheiro e uma pequena área de circulação mesclada ao lavabo. Portanto, a área reduzida das unidades impossibilita a disposição de layouts, pois, na maioria dos casos os mobiliários possuídos pelos usuários não se adaptam aos espaços correspondentes.

Já na Figura 4, observa-se que a área de circulação é bastante conflitante quando observados os fluxos, pois é nela onde ocorre o afunilamento. Devido ao seu modelo construtivo, as paredes dos quartos são compartilhadas com a unidade vizinha, ocasionando um desconforto sonoro devido ao não tratamento acústico e a alvenaria autoportante impossibilita a ampliação dos ambientes pré-estabelecidos. Dessa forma, as unidades são alvos de uma vasta gama de fragilidades se comparadas às potencialidades positivas que 0 conjunto poderia vir a ter. 


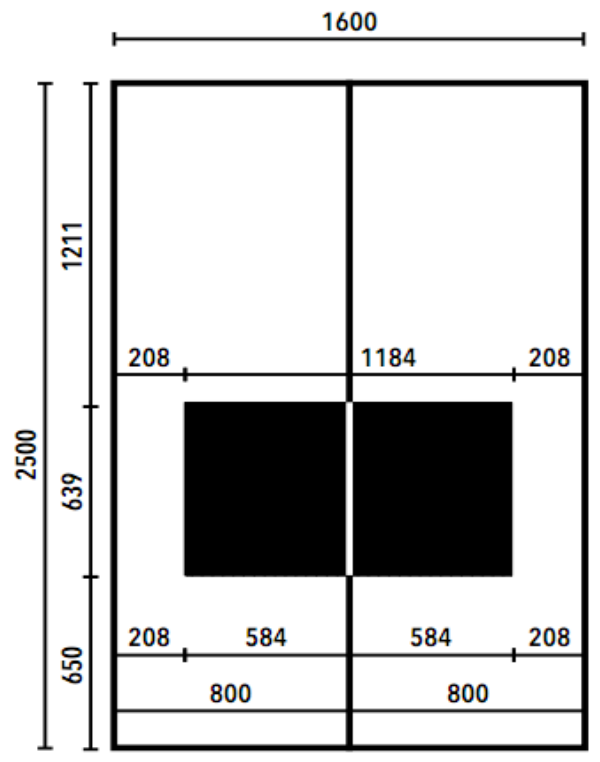

Figura 3 - Dimensões do lote e posicionamento da unidade Fonte: ARANTES, 2016.



Figura 4 - Esboços de cruzamentos de fluxos

Fonte: VILLA, S. B. et al., 2017.

Por fim, outra problemática apresentado em tal conjunto é que as unidades habitacionais foram entregues antes da conclusão das escolas, postos de saúde e policiamento, além de outros suportes geradores de urbanidade, o que fez com que os novos moradores necessitassem de grandes deslocamentos diários para o acesso a serviços, ao trabalho e ao lazer.

\section{O CONJUNTO HABITACIONAL PAULO FREIRE E O PROJETO PARTICIPATIVO}

O distrito da cidade de Tiradentes abriga um grande complexo de conjuntos habitacionais, dentre os quais está instalado o conjunto Paulo Freire em São Paulo, que surge a partir do movimento dos moradores de diversos bairros, financiado pelo FNHIS. Historicamente, o bairro Tiradentes recebeu da prefeitura a construção de duas mil unidades habitacionais. Entretanto, o mutirão Paulo Freire, composto pela união do Movimento dos Sem Terra Leste 1 de São Paulo, juntamente com a União dos Movimentos de Moradia (UMM), ocupou e conquistou parte desse lote para produzir habitações em sistema de mutirão.

O lote conquistado foi um terreno relativamente pequeno, que contava com um projeto para a construção de cem apartamentos de $42 \mathrm{~m}^{2}$ de área construída. Em contraponto, por meio de atividades organizadas o mutirão adotou um modelo de autogestão. A partir de então, a associação contou 
com assessorias arquitetônicas da USINA CTAH para discutir um projeto completamente diferente.

No novo projeto foi levado em conta o programa de necessidades dos moradores, resultando em três tipologias distintas, com unidades de $56 \mathrm{~m}^{2}$, com um ou dois dormitórios, com possibilidade de cozinha conjugada e unidades inteiramente moduladas, conforme mostram as Figuras 5,6 e 7 respectivamente.



Figura 5 - Tipologias arquitetônicas

Fonte: Baratto, 2017.

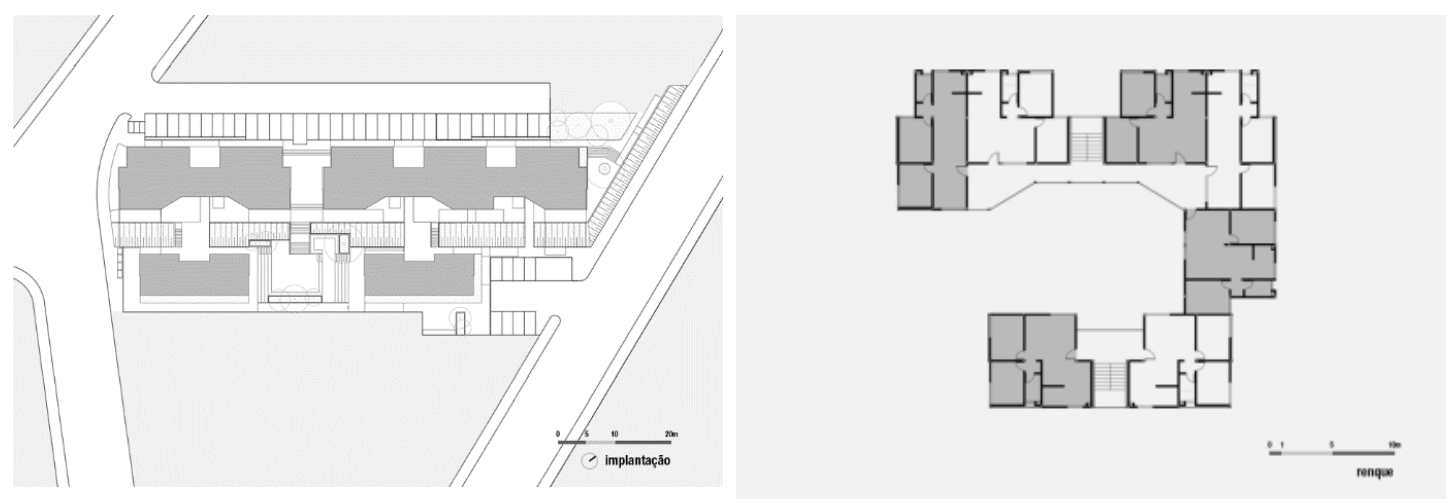

Figura 6 e Figura 7 - Modulação das unidades

Fonte: Baratto, 2017.

Um diferencial adotado na concepção arquitetônica foi o uso de estrutura metálica como elemento principal, pela necessidade de vencer maiores vãos, além possibilitar a elevação do edifício, liberando o térreo para áreas de convivência em comum para os moradores.

O projeto participativo trouxe junto com si a convivência entre os envolvidos, criando vínculos íntimos e promovendo o conhecimento de uns aos outros. Tal vínculo é observado nas relações de vizinhança existentes desde a inauguração do projeto, havendo constante vitalidade e urbanidade no dia a dia. Segundo Jacobs (2014), essa vitalidade é representada pela constante presença de pessoas na rua e seus vínculos geram um sentimento de segurança, além do sentido de pertencimento, proporcionado pela interação constante das fases projetuais e por se tratar de moradores já existentes ao local. Assim, o conjunto conta com as famílias participantes que se sentem 
pertencentes ao local onde vivem, têm orgulho e participam ativamente das relações que a vida urbana pode oferecer.

Em contrapartida, para Gonçalves (2015), sua localização é um pouco distante em relação ao centro da cidade de São Paulo, analisado na Figura 8, de aproximadamente $30 \mathrm{~km}$, o que dificulta o acesso por ser distante dos meios de transporte público, como metrô ou trem, uma vez que a estação mais próxima do conjunto fica a $10 \mathrm{~km}$ de distância.

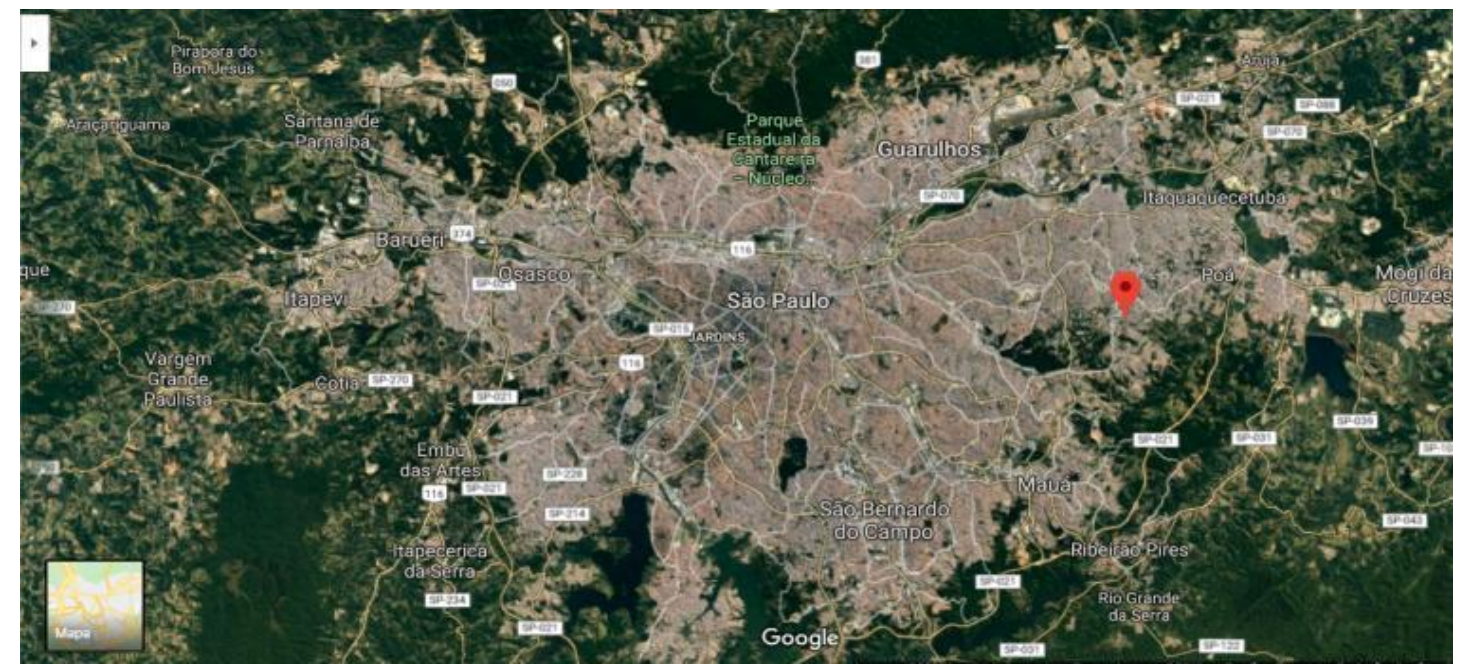

Figura 8 - Localização do conjunto habitacional Paulo Freire em relação a cidade de São Paulo

Fonte: Google Maps, 2019

Embora o local seja considerado apático em termos de urbanidade e pobre em arquitetura, no início do seu projeto, após a construção da obra, ele se tornou âncora para seu entorno. A redondeza que o circundava alavancou em desenvolvimento e acompanhou o progresso urbano que o conjunto habitacional proporcionou em meios de método, no qual abasteceu a área de serviços melhorando a qualidade de vida dos moradores.

Portanto, o conjunto possui uma boa inserção urbana provida de equipamentos urbanos de educação, saúde, lazer e cultura, além de ser conectado à malha urbana, porém pouco acessivel por transporte público. Relacionando-se a qualidade arquitetônica ao processo coparticipativo, o resultado obtido foi a concepção de unidades habitacionais com implantação e estruturas bem resolvidas, com bom conforto térmico e ambiental, tudo isso com um valor de custo inferior aos conjuntos que são habitualmente construídos por empreiteiras.

\section{CONSIDERAÇÕES FINAIS}

Vê-se que, desde a origem, os dois conjuntos habitacionais são díspares. O Shopping Park resulta de processo centralizado, gerido pelo poder público municipal em parceria com grandes construtoras, e que partem de um morador idealizado, com necessidades pré-determinadas, e o conjunto Paulo Freire tem sua origem vinculada aos movimentos sociais e pautada em um programa de autogestão.

No primeiro caso, a construção e povoamento do bairro vem de um processo de segregação desde a implantação unilateral do loteamento, perpassando pela seleção dos moradores e chegando à fase de entrega, na qual os usuários recebem um conjunto habitacional apático e desprovido de serviços 
básicos, como mercados, farmácias e outros. A única tipologia arquitetônica é representada pela adoção de um indivíduo uno, como se todos os moradores correspondessem a um tipo ideal, sem compreensão de que se está construindo cidade e promovendo relações sociais. Além da monofuncionalidade, como a ausência de diversidade no bairro, ruas mal iluminadas, quarteirões longos, excesso de espaços residuais e indivisibilidade entre espaços públicos e privados são elementos que corroem a urbanidade no local.

No segundo, a criação de um grupo com fortes laços sociais, consolidados durante o próprio processo de projeto e de construção da habitação e das relações cotidianas, geram o essencial para a garantia da vitalidade do espaço habitado (JACOBS, 2014). A concepção de diferentes tipologias representa o entendimento da multiplicidade social, o que ocasiona a pluralidade necessária ao alcance do alto grau de urbanidade.

Nota-se que esses conjuntos partem de diferentes concepções de cidade. Enquanto o Shopping Park é essencialmente tradicionalista e influenciado pelos princípios modernos do urbanismo, no qual o zoneamento da cidade define as funções de cada parte dela, o conjunto Paulo Freire, embora seja mais antigo, assume visão mais contemporânea de cidade e valoriza a diversidade funcional, tipológica e social, dando ênfase às relações coletivas e na apropriação do espaço público.

A partir das avaliações positivas e negativas dos modelos discutido, faz-se necessária a construção de um modelo de gestão baseado na participação popular em nível de planejamento e construção de moradias. Trata-se de projeto participativo, no qual o usuário desempenha papel ativo durante a elaboração e execução do projeto, em que atenderia diversos grupos de usuários, ocasionando maiores vínculos identitários e de pertencimento ao território, compreendendo as necessidades culturais e sociais específicas. Portanto, conclui-se que é papel fundamental do planejamento urbano na escala macro e micro evitar a produção desigual dos espaços urbanos.

\section{REFERÊNCIAS}

AGUIAR, Douglas. Urbanidade e a qualidade da cidade. Revista Vitruvius Arquitextos, São Paulo, n. 141.08, ano 12, mar. 2012. Disponível em: http://www.vitruvius.com.br/revistas/read/arquitextos/12.141/4221. Acesso em 4 jun., 2019.

BARATTO, Romullo. USINA 25 anos - Mutirão Paulo Freire. ArchDaily, jun. 2015. Disponível em: <https://www.archdaily.com.br/br/767957/usina-25-anosmutirao-paulo-freire>. Acesso em: 4 jun., 2019.

BARONE, A..; DOBRY, S. Arquitetura participativa na visão de Giancarlo de Carlo. Revista do Programa de Pós-Graduação em Arquitetura e Urbanismo da FAUUSP, São Paulo, v. 15, p. 18-31, 2005.

BONDUKI, Nabil. Habitat: as práticas bem-sucedidas em habitação, meio ambiente e gestão urbana nas cidades brasileiras. São Paulo: Studio Nobel, 1977.

GONÇALVES, Larissa S. Avaliação de qualidade de habitação de interesse social por meio de estudo de caso de mutirão auto gerido: inserção urbana, implantação e unidade habitacionais. Revista Nacional de Gerenciamento de Cidades, v. 03, n. 22, 2015. 
JACOBS, J. Morte e vida de grandes cidades. 3. ed. São Paulo: WMF Martins Fontes, 2011.

MALARD, M.; SANTOS, A.; PONTES, M. Autogestão habitacional e gestão de projetos: conflitos e compatibilidades. 2006. Disponível em:

<http://www.arq.ufmg.br/eva/art008.pdf>. Acesso em: 4 jun., 2019.

VILLA, S. B. et al. Método de análise da resiliência e adaptabilidade em conjuntos habitacionais sociais através da avaliação pós-ocupação e coprodução. Relatório final de pesquisa. Uberlândia: Universidade Federal de Uberlândia; Universidade de Sheffield, 2017.

VILLA, S.; SARAMAGO, R.; CASASANTA, L. Avaliação pós-ocupação no programa Minha Casa Minha Vida: uma experiência metodológica. Uberlândia: UFU/PROEX, 2015. 